\title{
Altering the Human Genome: Mapping the Genome Editing Regulatory System in South Africa
}

\author{
BA Townsend ${ }^{\star}$ and B Shozi ${ }^{\star *}$
}

\section{P.E.R}

Pioneer in peer-reviewed,

open access online law publications

Authors

Beverley Townsend and

Bonginkosi Shozi

Affiliation

University of KwaZulu-Natal, South Africa

Email

bev@greymatter.co.za

214511633@stu.ukzn.ac.za

Date Submission

4 November 2020

Date Revised

23 February 2021

Date Accepted

23 February 2021

Date published

29 March 2021

Editor Prof O Fuo

How to cite this article

Townsend BA and Shozi B

"Altering the Human Genome:

Mapping the Genome Editing

Regulatory System in South Africa"

PER / PELJ 2021(24) - DOI

http://dx.doi.org/10.17159/1727-

3781/2021/v24i0a9179

Copyright

DOI

http://dx.doi.org/10.17159/1727-

$3781 / 2021 / v 24 i 0 a 9179$

\begin{abstract}
Novel therapeutic strategies using genome editing technologies, such as CRISPR-Cas9 are revolutionising the way in which diseases can be prevented and treated in the future. Consequently, a global debate has emerged around the ethical and legal implications relating to the use of such technology in research, therapy, and human reproduction. This has brought to the forefront questions regarding the extent to which current policies respond to these issues. In this article we provide a "map" of South African policy relating to genome editing, and illustrate how current ethical guidelines and law regulate its use. We find that the South African legal and policy framework is marred with inconsistencies and incompleteness, and that an opportunity exists for the normative and regulatory framework governing this field of research and therapeutic application in South Africa to be reviewed and reformed. In this article we present certain recommendations - with the goal of informing and supporting health policy and decision-making regarding the regulation of genome editing in South Africa. We suggest that by adopting a pragmatic regulatory approach such recommendations serve to address public concern, reflect appropriate international perspectives, and provide a firm foundation for the development of genome editing regulation in South Africa.
\end{abstract}

\section{Keywords}

CRISPR-Cas9; genome editing technology; policy-making; National Health Act 61 of 2003; South Africa. 


\section{Introduction}

Recent developments in genome editing techniques, such as CRISPRCas9, are transforming biological therapeutic medicine. These technologies enable precisely targeted alterations to genomic sequences in living cells. The genome consists of sequences of DNA with specific functions that produce the proteins needed to carry out various activities in the cells of living organisms. Genome editing is the deliberate manipulation or alteration of a selected DNA sequence in the genome. This involves cleaving a section of DNA at a targeted location and altering the genomic sequence by inserting new DNA at a specific site. Such technologies, used in conjunction with precision medicine, can provide personalised preventative, diagnostic and therapeutic interventions to an individual in a predictive and precise manner. ${ }^{1}$

Given the rapid development of genome editing technology, the regulatory framework governing its application requires progression from a liminal (or transitional) state to one that can better provide for the eventualities such technological developments offer. As such, the purpose of this article is to provide a "map" of the current law relating to human genome editing, in the form of an overview of the existing regulatory framework relating to genetic manipulation for research, therapy, and human reproduction in South Africa. We aim to provide clarity on how activities related to genome editing are currently regulated; to identify gaps in the law and ethical guidance in this area; and to lay a solid foundation for ethically responsible policy development in genome editing that resonates with the values of the Constitution of the Republic of South Africa, 1996 (hereafter, the Constitution). In so doing, we seek: to describe the subject matter that requires redress (that is, novel genome editing therapies); to identify the existing means by which genome editing therapies are regulated in South Africa; to raise concerns with regard to the sufficiency of the normative framework that regulates the application of such therapies in South Africa; and to consider how to support and inform policy-making through a process of public engagement.

\footnotetext{
Beverley A Townsend. BA LLB LLM PGDip LLM PhD (UCT). Post-doctoral Fellow with the African Health Research Flagship, University of KwaZulu-Natal, South Africa. Email: bev@greymatter.co.za. https://orcid.org/0000-0002-8486-6041.

** Bonginkosi Shozi. LLB LLM (UKZN). Doctoral Fellow with the African Health Research Flagship, University of KwaZulu-Natal, South Africa. Email: 214511633@stu.ukzn.ac.za. https://orcid.org/0000-0003-2994-0795.

$1 \quad$ Blasimme and Vayena 2016 Perspect Biol Med 172-188.
} 
This article is divided into four parts. First, we describe the pre-eminent genome editing technology, CRISPR-Cas $9,{ }^{2}$ and its application in the emerging field of precision medicine. In the second part we examine the extant regulatory framework that governs human genome manipulation in South Africa, particularly with regard to the alteration of somatic and germline cells for therapeutic and research purposes. Third, we outline the global discourse regarding the regulation of genome editing and consider the applicability of policy recommendations such as moratoria in South Africa. In the fourth and final part, and in responding to the gaps identified in the regulatory framework, we consider the application of deliberative public engagement as a mechanism both to include the public and to ensure that its views are considered. We suggest that deliberative public engagement allows for the determination of values that are deeply embedded in our society and which ought to inform regulatory policymaking.

\section{Part 1: Genome editing technology and precision medicine}

Clustered Regularly-Interspaced Short Palindromic Repeats (CRISPR)associated RNA-guided endonuclease Cas9 (CRISPR-Cas9) is a precision RNA-guided genome editor or genomic modification editing technology. ${ }^{3}$ It uses proteins and short guide RNAs to mark DNA sequences, and to facilitate RNA-guided site-specific DNA binding and cleavage in a wide range of organisms. ${ }^{4}$ CRISPR-Cas 9 has been shown to enable the rapid and inexpensive manipulation of the genomes of individual organisms with accuracy, certainty and efficiency. ${ }^{5}$ CRISPR-Cas9 comprises two fundamental components. The first part comprises a molecular guide and a piece of RNA that locates and targets a predetermined sequence of the double-stranded DNA that is to be edited in the genome of an organism.

2 We acknowledge that there are several other genetic technologies, such as zinc finger nuclease (ZFN), transcription activator-like-effector based nucleases (TALEN), and prime editing, which may be used in human genome editing. However, we focus our analysis on CRISPR-Cas9, as this particular technology is the one most commonly referred to in the literature and the general public is typically familiar with it. Although we refer to CRISPR-Cas9, CRISPR based genome editing has since developed beyond the use of the Cas9 enzyme, and hence the common reference to CRISPR-Cas X.

3 Liu et al 2019 Nature 218-223, where a third RNA-guided genome-editing platform named CRISPR-CasX was revealed in early 2019 with an enzyme family that is comparatively smaller and functionally distinct from its Cas9 and Cas12a predecessors; also see Doudna and Charpentier 2014 Science 1077.

$4 \quad$ Gupta and Musunuru $2014 \mathrm{~J}$ Clin Invest 4154-4161; Cong et al 2013 Science 819823.

$5 \quad$ Hsu et al 2014 Cell 1262-1278. 
The second is an enzyme or protein that adheres to the pre-selected targeted section of the DNA and splices it. Cas9 is the enzyme that is used as a molecular scalpel to execute a neat, blunt cut. ${ }^{6}$

By using CRISPR-Cas9, precise and targeted manipulations of DNA sequences and novel pathways for therapeutic strategies can be developed by easily targeting and then modifying a genomic sequence by changing the guide RNA. Using the RNA molecules as a template, sequence-specific cuts in the DNA molecules are made, where a section of the gene can then be deleted and new sequences inserted - thereby altering the nucleotide sequence at the incision site. ${ }^{7}$ Thus, genome editing therapy allows scanning for deleterious genes and removing or correcting them. A further advantage of CRISPR-Cas9 is its ability to target and edit multiple genomic sites simultaneously by using several guide sequence RNAs in parallel in a single genome. ${ }^{8}$

Precision medicine is a healthcare model that seeks to target individuals rather than a generic patient by using genetic tools to make medicine more predictive, preventive and precise. By integrating multiple data sources with a molecular analysis of disease biology, therapeutic treatment plans can be tailored to the individual characteristics of a patient. ${ }^{9}$ Genome editing technologies, in conjunction with precision medicine, offer the opportunity to provide targeted, therapeutic applications to individuals, which may result in rapid and broad adoption across multiple sectors. ${ }^{10}$

Applications of genomic editing in the prevention and treatment of disease, facilitated by more accurate cellular models of pathological processes and the adoption of novel therapeutic strategies, are expanding with the expectation that genome editing will increasingly become more widely accessible. ${ }^{11}$ The application of target genome editing technologies extends beyond research and biomedical therapies. The emergence of genome editing into clinical medicine and the ability to modify genetic variants is progressing rapidly. ${ }^{12}$ Editing the human genome can alter the future of

Jinek et al 2013 eLife; Cribbs and Perera 2017 YJBM 625-634.

Caplan et al 2015 Sci Soc 1421-1426.

Cong et al 2013 Science 819-823; Gupta and Musunuru 2014 J Clin Invest 4154-

4161; Hsu et al 2014 Cell 1262-1278.

Ashley 2016 Nat Rev Genet 507-522.

Feeney 2018 AJOB 36-48.

Lander 2016 Cell 18.

CRISPR-Cas9 has been shown to be effective in genetic alteration in the cells of multiple organisms, including bacteria, fruit flies, zebrafish and animal models such as mice. See Reardon 2016 Nature 160-163; Hwang et al 2013 Nat. Biotechnol. 227229; Sanchez-Rivera and Jacks 2015 Nat Rev Cancer 387-395; Carroll 2014 Annu 
mankind, with the hope of not only eliminating suffering, but also promoting human flourishing. ${ }^{13}$ Although not without controversy, genomic editing technologies offer potential benefit to vast sectors of the population. ${ }^{14} \mathrm{How}$ then are such technologies regulated? We now consider the existing regulatory position in South Africa.

\section{Part 2: Regulatory position in South Africa: legal regulation and ethical guidance}

The regulatory position with regard to genome editing in South Africa has been described as "ambiguous", and rightfully so. ${ }^{15}$ Although various policy instruments refer to activities related to genomic manipulation, South Africa does not have specific genome editing legislation. Aspects of human genome manipulation are primarily regulated by the National Health Act ${ }^{16}$ and its regulations. ${ }^{17}$ Additional legislation may also be relevant to varying degrees, including the Medicines and Related Substances Control Act, ${ }^{18}$ the Children's Act, ${ }^{19}$ the Protection of Personal Information Act, ${ }^{20}$ the Patents

Rev Biochem 409-439; Caplan et al 2015 Sci Soc 1421-1426; Mali et al 2013 Science 823-826. Lander 2015 NEJM 5.

14 See Evans et al 2011 Science 862 for the need to evaluate the promise of genomics through a realistic lens, and to separate unrealistic expectations from reality. It is, however, anticipated that it will take time for the full potential of DNA-based transformation in healthcare to be realised. See Araki and Ishii 2014 Reprod Biol and Endocrinol 9.

National Health Act 61 of 2003 (the NHA).

NHA Ch 8 and its Regulations created in terms of s 68. In this regard, particularly, the Regulations relating to the Use of Human Biological Material (the Use of Human Biological Material Regulations) (GN R177 in GG 35099 of 2 March 2012); Regulations regarding the General Control of Human Bodies, Tissue, Blood, Blood Products and Gametes (the General Control Regulations) (GN R180 in GG 35099 of 2 March 2012). In addition, the following regulations find application to various degrees: Regulations relating to the Artificial Fertilisation of Persons (the Artificial Fertilisation Regulations) (GN R175 in GG 35099 of 2 March 2012); Regulations relating to the Registration of Microbiological Laboratories and the Acquisition, Importation, Handling, Maintenance and Supply of Human Pathogens (the Pathogens Regulations) (GN R178 in GG 35099 of 2 March 2012); Regulations relating to Blood and Blood Products (the Blood Regulations) (GN R179 in GG 35099 of 2 March 2012); Regulations relating to the Import and Export of Human Tissue, Blood, Blood Products, Cultured Cells, Stem Cells, Embryos, Foetal Tissue, Zygotes and Gametes (the Import and Export Regulations) (GN R181 in GG 35099 of 2 March 2012); Regulations relating to Tissue Banks (the Tissue Banks Regulations) (GN R182 in GG 35099 of 2 March 2012); and the Regulations relating to Stem Cell Banks (the Stem Cell Banks Regulations) (GN R183 in GG 35099 of 2 March 2012). Medicines and Related Substances Control Act 101 of 1965 (the MCA). Children's Act 38 of 2005.

Protection of Personal Information Act 4 of 2013 (POPIA). 
Act, ${ }^{21}$ and the Consumer Protection Act. ${ }^{22}$ Ethical guidelines also find application. These include the HPCSA Guidelines, ${ }^{23}$ the DOH Guidelines, ${ }^{24}$ and the Medical Research Council Guidelines on Ethics in Reproductive Biology and Genetic Research. ${ }^{25}$ In this article we focus only on the extant law and ethical guidance regarding the editing of human somatic cells and germline cells (that is, gametes (ova and sperm), zygotes and embryos).

\subsection{Legislation: National Health Act and the regulations}

The NHA, enacted in 2004, in Chapter 8 and in a series of regulations made in 2012 pursuant thereto, regulates inter alia the removal and application of tissue, blood, blood products or gametes from living persons. The NHA prohibits the reproductive cloning of human beings or research on human embryos in vitro after 14 days. ${ }^{26}$

\subsubsection{Reproductive and therapeutic cloning}

At the outset, it is opportune to begin by stating that South African legislation prohibits reproductive cloning - a position probably motivated by the global media outcry around the creation of Dolly the sheep, the first cloned mammal. ${ }^{27}$ This prompted a response at an international level in the form of the UN Declaration on Human Cloning, which prohibits all forms of human cloning, a position which is mirrored in many jurisdictions globally. ${ }^{28}$ Although South Africa abstained from voting on the United Nations Declaration on Human Cloning on the grounds that the language of the text was deliberately ambiguous, thereby infringing on the rights of those jurisdictions which wished to pursue research objectives, it was confirmed that South Africa "was against reproductive human cloning and would continue with the strict regulation of therapeutic cloning." The South African delegation to the UN affirmed that therapeutic cloning is aimed at protecting human life and, as such, adopted a position which in principle was not

\footnotetext{
$21 \quad$ Patents Act 57 of 1978.

22 Consumer Protection Act 68 of 2008.

23 The HPCSA published a code of ethical practice for medical biotechnology research in South Africa in 2008. HPCSA 2008 https://www.sada.co.za/media/documents/HPCSA_Booklet_14_Biotechnology_Re search_in_SA.pdf (HPCSA Booklet 14).

24 Department of Health Ethics in Health Research (the DOH Guidelines).

25 MRC $2001 \quad \mathrm{http} / / /$ www.mrc.ac.za/sites/default/files/attachments/2016-0629/ethicsbook2.pdf (MRC Book 2).

26 Sections $57(1)$ and (4) of the NHA.

$27 \quad$ Hopkins 1998 Hastings Centre Report 6.

28 United Nations Declaration on Human Cloning (2005); See Araki and Ishii 2014 Reprod Biol Endocrinol 9 for the international regulatory landscape.
} 
inconsistent with the Declaration. ${ }^{29}$ This it has achieved by stipulating in the $\mathrm{NHA}$ that human reproductive cloning is legally not permissible.

The provisions in the NHA regarding reproductive and therapeutic cloning are:

i) The "reproductive cloning of a human being" is defined as:30

the manipulation of genetic material in order to achieve the reproduction of a human being and includes nuclear transfer or embryo splitting for such purpose.

The NHA states: ${ }^{31}$

A person may not -

(a) manipulate any genetic material, including genetic material of human gametes, zygotes or embryos; or

(b) engage in any activity, including nuclear transfer or embryo splitting,

for the purpose of the reproductive cloning of a human being.

To clarify, in terms of the NHA it is prohibited to manipulate gametes, zygotes, or embryos in order to achieve the reproduction of a human being, that is, for the purposes of reproductive cloning. It is also prohibited to engage in any activity, including nuclear transfer or embryo splitting, for the purposes of reproductive cloning. The proviso "for the purpose of reproductive cloning of a human being" applies to both (a) and, independently, to (b) above. It is conceivable that one could thus perform (a) and/or (b) for purposes other than reproductive cloning. This is to suggest that the manipulation of genetic materials using genome editing technologies, for instance, which does not result in the "reproductive cloning of a human being" is permitted.

ii) It is prudent at this juncture to establish how the NHA not only defines "reproductive cloning" in particular, but also, "therapeutic cloning". The "reproductive cloning of a human being" is specifically defined as: 32

UN 2005 https://www.un.org/press/en/2005/ga10333.doc.htm.

Section 57(6)(i) of the NHA.

Section 57(1) of the NHA.

Section 57(6)(a) of the NHA. 
the manipulation of genetic material in order to achieve the reproduction of a human being and includes nuclear transfer or embryo splitting for such purpose.

"Therapeutic cloning" is defined in the NHA as: ${ }^{33}$

the manipulation of genetic material from either adult, zygotic or embryonic cells in order to alter, for therapeutic purposes, the function of cells or tissues.

The definition of "therapeutic cloning" is broad and would include genome editing therapies. The only instance in which "therapeutic cloning" is referred to in the NHA is in section 57(2), where it is provided that the Minister of Health may permit therapeutic cloning, that is the manipulation of genetic material from adult or umbilical cord stem cells, under such conditions as he may prescribe. ${ }^{34}$ The definition of "therapeutic cloning" includes the manipulation of "either adult, zygotic or embryonic cells" and is ostensibly for all therapeutic purposes. Neither the NHA nor the regulations make any further reference to the term "therapeutic cloning" per se.

Is a reproductive purpose different from that of reproductive cloning?

The NHA does not preclude the manipulation of genetic material for reasons or purposes other than reproductive cloning. "Reproductive cloning" is defined as: ${ }^{35}$

the manipulation of genetic material in order to achieve the reproduction of a human being and includes nuclear transfer or embryo splitting for such purpose.

What the definition suggests is that where such manipulation and/or activity is to "achieve the reproduction of a human being", that is, where the desired result is in "reproducing" and presumably "replicating" a human being, it is an act of reproductive cloning.

Does section 57 of the National Health Act amount to a prohibition on germline genome editing?

The ambiguity of the law relating to genome editing in South Africa emanates in part from the imprecise wording used in section 57 of the NHA. ${ }^{36}$ The definition of "reproductive cloning" is broad, and may be interpreted such that any manipulation of genetic material which results in the reproduction of a human being would fall within the bounds of this

Section 57(6)(b) of the NHA.

Section 57(2) of the NHA.

Section 57(6)(a) of the NHA.

See Pillay and Thaldar 2018 SAJBL 89-92. 
definition. This is because if one gives a literal interpretation to section $57(1)$ - read together with section 57(6) - this provision prohibits any person from manipulating genetic material "for the purpose of achieving the reproduction of a human being". In terms of this interpretation, "cloning" refers not to the ordinary meaning associated with the word, but rather to all forms of the manipulation of genetic material. Thus, the editing or manipulation of the human genome in germline cells using CRISPR-Cas9 for the purpose of achieving the reproduction of a human being would not be permissible.

While such an interpretation of section 57 would outlaw genome editing in humans, one should be cognisant of the fact that this section was drafted well before the advent of viable genome editing technologies, and would not have been drafted with this particular use of genomic technology in mind. In an attempt to prohibit human cloning, the legislature ostensibly cast the net wide. Thus, despite the prohibition of the cloning of gametes and embryos to be used in reproduction being the apparent purpose of section 57 , the wording of section 57(6) defining the reproductive cloning of a human being as "the manipulation of genetic material in order to achieve the reproduction of a human being" arguably brings germline genome editing within the scope of activities prohibited by section $57(1)$.

However, an alternative interpretation may well provide some clarity. This is because a literal interpretation is not the only way in which statutes may be interpreted in South African law in our new constitutional dispensation. Rather, case law provides for the application of a purposive approach. ${ }^{37}$ As the Constitutional Court stated in Bato Star Fishing (Pty) Ltd $v$ Minister of Environmental Affairs and Tourism: 38

the emerging trend in statutory construction is to have regard to the context within which the words occur, even where the words to be construed are clear and unambiguous.

This is an emphatic statement by a South African court that even where the wording of a provision is abundantly clear - which section 57 is far from being - our courts give effect not to the plain meaning of a legal provision but to the purpose of the provision by viewing it in context.

$37 \quad$ Natal Joint Municipal Pension Fund v Endumeni Municipality 20124 SA 593 (SCA) para 18. The ratio of this case has been endorsed as representing the current approach to statutory interpretation in South Africa on several occasions by our higher courts, including the recent Constitutional Court judgment of Cloete v S 2019 5 BCLR 544 (CC) para 28.

Bato Star Fishing (Pty) Ltd v Minister of Environmental Affairs and Tourism 20044 SA 490 (CC) para 91. 
We suggest that, notwithstanding the possibility that a literal interpretation given to "reproductive human cloning" would create a general prohibition on genetic manipulation resulting in human reproductive cloning (as defined), a purposive interpretation of the section may be applied. When one reads the section in context, and having regard to the purpose of the section, one is led to the conclusion that it was intended to apply only to human cloning and not to other forms of genetic manipulation such as genome editing. ${ }^{39}$ Such an interpretation of the scope of section 57 may also be preferred for the application of the long-standing common law principle that: ${ }^{40}$

if a statute is couched in ambiguous language, the court will give it the meaning which least interferes with the liberty of the individual.

In addition, the prohibition of germline genome editing would infringe inter alia on the rights of scientists to "freedom of scientific research" and the rights of parents to make "decisions concerning reproduction". As such, an interpretation that does not interfere with legally recognised liberties is the one which the principles of law enjoin us to give effect to. ${ }^{41}$

We do not take the view, here, that either of these interpretations of section 57 is necessarily correct, but simply outline them to illustrate why section 57 lacks clarity and needs urgent reform. To resolve the ambiguity in this provision and to give effect to the apparent purpose of section 57, we suggest an amendment to the NHA to allow for a more comprehensive definition of "human cloning"; 42 one that serves to differentiate "reproductive cloning" from other forms of reproductive genome therapies. In addition to this, there needs to be further policy development that specifically speaks to germline manipulation using technologies such as CRISPR-Cas9.

\subsubsection{Somatic and germline cells: therapies and research}

In terms of the Medicines and Related Substances Control Act, genome therapies are required to pass the rigorous tests of clinical trial and to be registered with the South African Health Products Regulatory Authority (SAHPRA). ${ }^{43}$ Various additional layers of restrictions and control pertaining

\footnotetext{
$39 \quad$ Natal Joint Municipal Pension Fund v Endumeni Municipality 20124 SA 593 (SCA) para 18.

40 Rossouw $v$ Sachs 19642 SA 551 (A).

41 Cool ldeas I 186 CC v Hubbard 20144 SA 474 (CC) para 28; Public Servants Association obo Ubogu v Head, Department of Health, Gauteng 20182 SA 365 (CC) para 43.

42 A similar definition is used in Canadian legislation, s 3 of the Canadian Assisted Human Reproduction Act, 2004.

43 Section 15 of the MCA.
} 
to the removal, storage, and preparation of biological materials and to their application in genetic research and therapeutic use are evident in the NHA and the Regulations.

Crucially, the NHA regulations do not specifically define or differentiate "germline" or "somatic" cells. ${ }^{44}$ It is thus left to the reader to extrapolate the regulatory position relevant to gene-based applications from the legislation and regulations in a fragmented and piece-meal manner. Most gene therapies would involve in combination, or in part, at least one of the following human biological materials: tissues, gametes, embryos/zygotes, and cells (be they somatic, germline and/or, stem cells). Although the NHA and the regulations do not refer specifically to germline cells, specific mention is most frequently made in the provisions to the terms "gametes", "embryos", "zygotes" and "embryonic stem cells".

Novel genetic therapies do not always sit comfortably within the definitions provided by the existing regulatory frameworks. The NHA and its regulations do not provide complete definitions of "genetic health research", "genetic testing", "therapeutic" or "health research purposes". This we suggest requires amendment.

\section{Somatic cells}

Genetic alterations made on human somatic cells (that is, all cells except gametes) are considered to be less ethically controversial than germline genome editing. ${ }^{45}$ Somatic genome editing therapies enable editing directed at the cells of genes responsible for certain cancers and infectious diseases. ${ }^{46}$ Modifications made in fully developed non-reproductive cells affect only the organism or person and are not heritable.

44 For ease of reference, a few definitions are provided: a "cell" means "the smallest structural and functional unit of an organism, consisting of cytoplasm and a nucleus enclosed in a membrane in living things"; "cultured cells" means "cells that have been grown outside the body"; DNA means "deoxyribonucleic acid, which is nucleic acid, composed of building blocks called nucleotides"; an embryo is "a human offspring in the first eight weeks from conception"; a zygote is the "product of the union of a male and female gamete"; "embryonic stem cells" means "any cell from the 30-200 inner cell mass of the blastocyst"; "foetus" means "a human offspring from eight weeks after conception until birth"; "progenitor cells" means "stem cells which give rise to a distinct stem cell line"; "stem cell" means "a cell that has both capacity to self-renew as well as to differentiate into mature, specialised cells"; and "umbilical cord blood stem cells" means "stem cells found in umbilical cord blood". Ishi 2016 Curr Stem Cell Rep 313-320. 
As genome editing therapies targeting somatic cells are a form of medical intervention, albeit patient-specific individualised precision treatment as opposed to mass-produced conventional medicine, the question to be raised is whether the clinical and therapeutic use of somatic cell therapies should be regulated in terms of the Medicines and Related Substances Control Act - either as a "medicine" or as a "medical device", as the case may be. ${ }^{47}$ Provision is also made for "health technology" in terms of the NHA, which means: 48

machinery or equipment that is used in the provision of health services, other than 'medicine' as defined in the Medicines and Related Substances Control Act.

Novel somatic gene-based cell therapies would be subject to safety, efficacy, control, and quality requirements, as is the case with all other medicine and existing regulatory mechanisms, and such standards will apply to somatic genome editing. ${ }^{49}$ As therapies on somatic cells are permitted, the inference is that research on somatic cells is also permissible. ${ }^{50}$

\section{Germline cells for research}

Germline cells are developed in the embryonic sex organs to form human sperm or ova (eggs). Germline genome editing is the alteration of the DNA of human sperm, ova/eggs, or embryos such that these inheritable genetic modifications can be transmitted to successive generations. Significant to gene-based research is the provision in the NHA that provides that the Minister of Health may permit research on zygotes which are not more than

47 Section 1 of the MCA. Definition of a "medical device" is "any instrument, appliance, material, machine, apparatus, implant or diagnostic reagent - (a) used or purporting to be suitable for use or manufactured or sold for use in -(i) the diagnosis, treatment, mitigation, modification, monitoring or prevention of disease, abnormal physical or mental states or the symptoms thereof; or (ii) restoring, correcting or modifying any somatic or psychic or organic function; or (iii) the diagnosis or prevention of pregnancy, and which does not achieve its purpose through chemical, pharmacological, immunological or metabolic means in or on the human body but which may be assisted in its function by such means; or (b) declared by the Minister by notice in the Gazette to be a medical device, and includes any part or an accessory of a medical device". Definition of "medicine" is "any substance or mixture of substances used or purporting to be suitable for use or manufactured or sold for use in - (a) the diagnosis, treatment, mitigation, modification or prevention of disease, abnormal physical or mental states or the symptoms thereof in man; or (b) restoring, correcting or modifying any somatic or psychic or organic function in man, and includes any veterinary medicine".

48 Section 1 of the NHA.

49 See Jordaan 2012 SAMJ 226-228.

50 HPCSA Booklet 14 para 13.3.1. 
14 days old, on a written application for research purposes, as long as the applicant undertakes to document the research and the donor's prior written consent has been obtained. ${ }^{51}$ It is presumed that research on an embryo (that is, one that is 14 days old or younger) is permitted, as long as implantation will not follow.

The Regulations state that gametes removed from living persons may be used only for medical and dental purposes including, in the case of a gamete, the artificial fertilisation of another person. ${ }^{52}$ In addition, a person may not carry out genetic health research unless such research has been approved by a registered health research ethics committee referred to in the NHA. ${ }^{53}$ The NHA establishes a National Health Research Committee to determine, develop, and co-ordinate the health research activities of public health authorities. ${ }^{54}$ Any excess embryos obtained from in vitro fertilisation may be used to produce embryonic stem cell lines for the purpose of research, provided that the competent person obtains written informed consent from the embryo donor or cord blood donor. ${ }^{55}$ Research conducted on primordial germ cells, i.e. stem cells found in the gonad (human testis or human ovary) of a foetus capable of becoming ova or sperm, and obtained from an aborted foetus, is permissible, but only with the prior written informed consent of the donor of the aborted foetus. ${ }^{56}$ The regulations are clear in the prohibition of selecting the sex of a child. However, whether a prohibition in this respect suggests that other types of selection or manipulation of DNA are allowed, subject to the regulations, remains a matter of legal conjecture.

\subsubsection{The 14-day rule}

In the field of human embryology regulation, the Warnock Report has for a number of years been used to inform legislation around the world. ${ }^{57}$ It is of particular influence in the ethical considerations around the delicate issues relating to the use of reproductive bioethics and technologies and in providing a benchmarking standard for embryonic research policy-making. Given that research using embryos is a necessity in the development of reproductive and therapeutic technologies, for reasons of pragmatism the

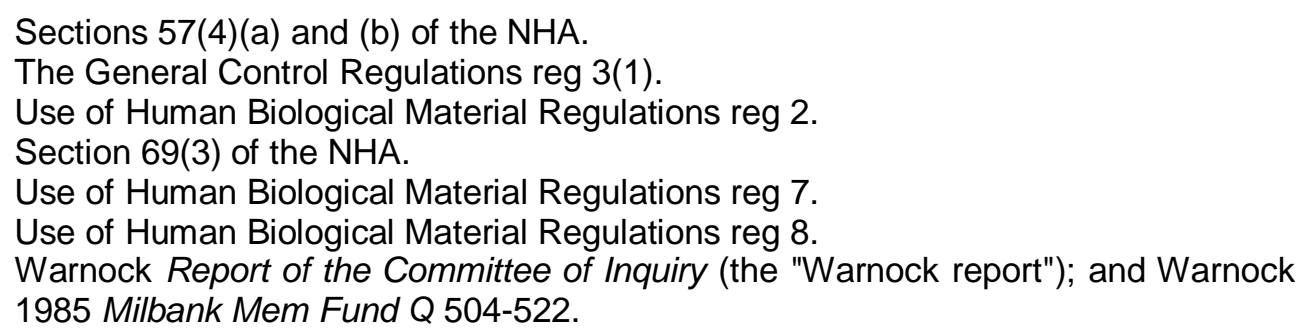


decision is to impose a 14-day limit, rather than a point in embryonic development, beyond which no further research on embryos is permitted. It is at this time that the appearance of the "primitive streak" (a formation of cells that is a precursor to the development of the spinal cord and nervous system) is first noticed. This is an indicator which can be used as a marker of individuality, as after its presentation the embryo can no longer split to form twins. Thus, an approach using 14 days of embryonic development as an end point beyond which no further research is allowed is both clear and can be consistently applied. Of late, the debate has been on whether it is prudent to extend the 14-day limit on embryo research. ${ }^{58}$ Nevertheless, in South Africa the NHA endorses the 14-day rule and research using human embryos older than 14 days from the time of fertilisation is not permitted.

\subsection{Ethical guidance: MRC and HPCSA Guidelines}

Notwithstanding the NHA express provision allowing for research on preembryos in certain circumstances as described above, the Health Professions Council of South Africa (HPCSA) published a code of ethical practice for biotechnology research in South Africa in 2008 (as Booklet 14), stating that "research relating to germline gene therapy is ... not acceptable". 59 Significantly, however, the HPCSA Guidelines anticipate therapeutic applications by providing that research with regard to gene therapy:

must only be directed to alleviating diseases in the individual patients and no attempts should be made through the use of gene modification to change human traits not associated with disease. ${ }^{60}$

This position is reiterated in the MRC Guidelines, which state that: ${ }^{11}$

any attempt by gene modification to change human traits not associated with disease would be unacceptable.

The MRC Book 2 addresses germline therapy, specifically stating in para 3.2.3 that "germline therapy should not be contemplated" and again in para

\subsubsection{1 that}

it is recommended that gene modification of the human germline should not yet be attempted until such time that it is clearly sanctioned in South Africa. ${ }^{62}$

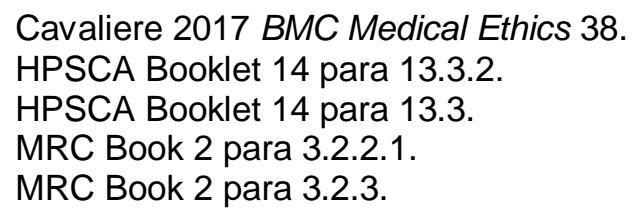


The concern is levelled primarily at the misuse of germline therapy in medical practice. ${ }^{63}$ Despite this, the MRC Book 2 adopts a somewhat more permissive approach by making the following reference to pre-embryo manipulation and research therapies: 64

[p]re-embryo manipulation and research may yield valuable medical information. However, it can be regarded as ethical only if the embryos are not specifically produced for the purpose of research. In addition, the embryos should not be transferred to the uterus unless there is reasonable certainty that the manipulation carries no potential risks for the foetus.

As germline editing is a type of manipulation, this suggests that germline edited embryos can be used for reproductive purposes ("transferred to the uterus"), but makes it subject to the condition that the germline editing should not carry risk to the foetus. As such, the guidelines seem not to place an outright ban on human germline editing.

\section{Part 3: South African position and international discourse on germline manipulation}

South African ethical guidelines generally reflect a cautious position aligned with current global thinking regarding germline editing. Ethical concerns in the emergence of novel therapies that re-engineer genomic sequences are noted. ${ }^{65}$ These include concerns over what may be considered to be the responsible use of the technology, and the consequential societal, legal, and ethical implications thereof. Although an entire spectrum of perspectives of what may be considered morally acceptable uses of genome editing exists, of particular difficulty is the application of genome editing to germline cells (that is, to heritable DNA such as ova, sperm, and zygotes/embryos) and the use of the technology in human cloning.

Members of the international scientific community have called for a global moratorium on all clinical human germline editing until such time as its safety and efficacy as well as the legal, social, and ethical implications of its use can be more carefully ascertained. ${ }^{66}$ The moratorium is predicated on the understanding that an international governance framework be

\footnotetext{
$63 \quad$ MRC Book 2 para 3.2.3.

$64 \quad$ MRC Book 2 para 2.17.

65 See $\quad$ Lander $2015 \quad$ NEJM 2018 https://www.theatlantic.com/science/archive/2018/11/first- gene- edited- babieshave- allegedly- been- born- in- china/576661.

66 An international moratorium on the clinical uses of human germline editing has been supported by the US National Institutes of Health; see Wolinetz and Collins 2019 Nature 175.
} 
developed. In the interim, and in terms of the moratorium, most have agreed to halt any clinical germline editing applications until such time as certain predetermined conditions can be met. ${ }^{67}$

The suggestion in the proposed moratorium is that the technical, scientific, medical, societal, ethical and moral issues be addressed by means of "broad societal consensus" and open public discourse. ${ }^{68}$ This with the understanding that decisions regarding policy regulation should "be informed by diverse interests and perspectives". 69 In this way the sovereignty of nations is respected and states are encouraged to develop their own national laws representative of public perspective and opinion. ${ }^{70}$ This is a sentiment which has been echoed in recent proposals for global governance on human genome editing made by the International Commission on the Clinical Use of Human Germline Genome Editing. ${ }^{71}$

The controversy with regard to germline editing is simply that although altering the DNA of embryos or gametes may permit parents who carry mutations to a genetic disease or condition, to have genetically related children who are mutation free, heritable gene editing of either embryos or gametes poses risks that are at this stage undetermined. The suggestion by the drafters of the moratorium is that: ${ }^{72}$

germline editing could produce unintended harmful effects for not just an individual but also for that individual's descendants,

with changes to a particular trait having: ${ }^{73}$

unanticipated effects on other traits that could vary from person to person and in response to environmental influences.

Whereas the application of genomic editing in somatic cells is not typically ethically problematic, the moratorium on germline editing is to allow the ethical and governance implications associated with human germline genome editing to be established. ${ }^{74}$ Certain countries prohibit the germline

67 Baltimore et al 2015 Science 36-38. Lander et al 2019 Nature 165-168.

68 This proposed moratorium does not extend to the genetic editing of human somatic (non-reproductive) cells for therapeutic purposes, or to the editing of germ line cells for research purposes - provided that the study does not involve the transference of an embryo to a human uterus.

Lander et al 2019 Nature 167.

Lander et al 2019 Nature 168.

NASEM Heritable Human Genome Editing.

NASEM Second International Summit on Human Genome Editing 7.

NASEM Second International Summit on Human Genome Editing 7.

Baumann 2016 Nano Ethics. 
alteration of human embryos for reproductive purposes, with the application of germline editing for non-therapeutic purposes also considered unacceptable in many countries. ${ }^{75}$

A statement by the Organising Committee of the International Summit on Human genome editing (released on November 2018), reconfirmed that any clinical use of heritable germline editing is "irresponsible" and called for continued international discussion of the benefits, risks, and oversight. ${ }^{76}$ Nevertheless, the statement anticipates that germline gene editing may in the future become acceptable where the risks associated with such a process have been ascertained and addressed, and in the case of strict independent oversight, there is a compelling medical need, an absence of reasonable alternatives, a plan for long-term follow-up, and attention to societal effects. However, at this time the report concludes that the clinical practice of germline editing is not permitted, as the risks are considered too uncertain. Despite this, the statement acknowledges that "public acceptability will likely vary among jurisdictions, leading to differing policy responses". ${ }^{77}$

\section{Part 4: The role of public engagement to inform policy- making in South Africa}

Increasingly, there is an effort to engage the public in areas of complex and controversial technological decision-making. ${ }^{78}$ Given the unprecedented and persistent interest and public concern over germline alteration, it is necessary to determine what applications are considered acceptable, and how the ethical concerns regarding the use of this technology can be suitably regulated through an inclusive and participative approach to policy formation. To understand and mitigate the risks and allay public fears arising from the use of genome editing technology, a process of informed public engagement is endorsed whereby meaningful public debate is used as a mechanism, and in an attempt to answer some of the more pressing moral, ethical and policy questions surfacing from rapid scientific and technological advancements. ${ }^{79}$ Effective public dialogue can thus increase the legitimacy

\footnotetext{
Nature Medicine 2015 Nat Med 295.

NASEM Second International Summit on Human Genome Editing 7. NASEM Second International Summit on Human Genome Editing.

See, for example, the consultation process undertaken by the WHO in the development of the first draft of its global governance framework: WHO Advisory Committee 2020 https://www.who.int/docs/default-source/ethics/governanceframework-for-human-genome-editing-2ndonlineconsult.pdf?ua=1. 
of policies by directing new or reforming existing regulatory frameworks. ${ }^{80}$ Public inclusion would thus ensure that policies at the very least take societal views into account, which is significant in the implementation of ethically acceptable genome editing regulatory policies. ${ }^{81}$ However, open and inclusive decision-making can neither resolve the underlying uncertainties nor mitigate the risks of genome editing adoption. ${ }^{82}$ Furthermore, public opinion may guide legal and ethical frameworks relating to genome editing only insofar as they do not infringe on the fundamental rights of researchers, patients, and prospective parents - meaning that even if the public does not approve of genome editing, this in itself is not a reasonably justified basis for prohibiting activities related to human genome modification. While public opinion is an integral part of law-making in South Africa, as in any constitutional democracy, ${ }^{83}$ in $S$ v Makwanyane ${ }^{84}$ it was made clear that the rights enshrined in the Constitution are so enshrined to shield them from the tyranny of the will of the majority.

In the majority judgment Chaskalson $\mathrm{J}$ comments on the role of public opinion in constitutional adjudication: 85

\begin{abstract}
If public opinion were to be decisive there would be no need for constitutional adjudication. The protection of rights could then be left to Parliament, which has a mandate from the public, and is answerable to the public for the way its mandate is exercised, but this would be a return to parliamentary sovereignty, and [be] a retreat from the new legal order established by the 1993 Constitution.
\end{abstract}

Accordingly, in cases where human rights are implicated, public opinion may and should influence policy decisions; however, it is not the decisive consideration. ${ }^{86}$ In showing due regard to the supremacy of the Constitution, and to avoid constitutional invalidity, any policy on human genome manipulation should be in line with the rights and values contained in the Constitution. Current attempts at gauging public perceptions of genome editing suffer from certain defects, such as a lack of a critical understanding of the questions put to participants. ${ }^{87}$ This is apparent even in developed countries like the US and the UK, and is likely to be an even greater issue

$80 \quad$ Posner et al 2016 PNAS 1760-1765.

81 See Cavaliere et al 2019 Camb Q Healthc Ethics 76-88.

82 See Van den Belt "Biotechnology" 185.

83 See Steiner 1988 Harv Hum Rts YB 77.

$84 \quad S$ v Makwanyane 19953 SA 391 (CC).

$85 \quad S$ v Makwanyane 19953 SA 391 (CC) para 88.

86 See the comments of Powell J in Furman v State of Georgia 408 US 238 (1972) 433, cited in S v Makwanyane 19953 SA 391 (CC) para 89. 
in South Africa, given challenges such as the low literacy rates and the language barriers. It is for this reason that we propose a process of public engagement based on deliberative democracy theory. ${ }^{88}$ This approach, referred to as deliberative public engagement, entails a departure from the conventional approach of seeking to obtain the will of the majority through a mechanism of "votes", and instead seeks to reflect the underlying values of a group through "communicative processes of opinion and willformation". ${ }^{89}$ This approach allows for discourse around these issues to occur, and thereby allows for participants to be properly informed about scientific developments and to critically engage with these issues rather than to form opinions in the abstract. We suggest such an approach would be best suited for public participation on complex bioethical issues such as genome editing in South Africa.

This approach, we propose, speaks to and supports a position of heightened collective cohesion and co-operation, both within societies and between them. These societal discussions and solutions might in turn feed into a global arena, where common issues, insights and values may be shared. We caution that the process does not mitigate the uncertainty inherent in the application of genome editing technologies, but merely establishes a value-based threshold that the public finds acceptable and which can inform regulatory policy-making. Furthermore, such a value framework must be in line with the Constitution, and where it fails to be in line, individual human rights ought not to be infringed based solely on public consensus.

\section{Conclusion}

In this article we have presented an introduction to the nascent science of CRISPR-based genome editing, which is poised to transform the field of precision medicine in the foreseeable future. With this in mind, we explored how this technology stands to be regulated in the South African context by discussing the most relevant provisions in the law. Such a discussion is necessitated by the fact that unravelling the plethora of complexities of genome editing regulation is not a simple task. However, mapping the genome editing regulatory system in South Africa is essential in order to better understand the normative position when altering the human genome.

88 Such an approach was adopted in Canada, in engaging with the communities of British Colombia on the ethical issues pertaining to human tissue banking. Burgess et al 2008 Pers Med 285. 
Although several statutes and regulations have a bearing on the legality of genome editing in South Africa, in each case the law fails to fully provide answers regarding what aspects of this emergent science are legal and acceptable in South Africa. In particular, the provisions of the NHA are worded such that they may potentially be applicable, but as we have demonstrated there is a strong argument for the position that genome editing falls outside the scope of the purpose of this statute.

Given the current inconsistencies and incompleteness of the regulatory framework concerning genome editing in South Africa, the opportunity exists for the development of an unambiguous, robust genome editing framework to fill in the "gaps". This framework, we suggest, should address public concern, reflect appropriate international perspectives, and represent the dynamic landscape of innovative genome modification in South Africa. Thus, building on the existing framework we suggest a position that encourages and promotes practices and responsible technological innovation, and which supports decision-making by engaging the public in better policy-making.

\section{Bibliography}

\section{Literature}

Araki and Ishii 2014 Reprod Biol Endocrinol

Araki $\mathrm{M}$ and Ishii $\mathrm{T}$ "International Regulatory Landscape and Integration of Corrective Genome Editing into in vitro Fertilization" 2014 Reprod Biol Endocrinol 1-12

Ashley 2016 Nat Rev Genet

Ashley E "Towards Precision Medicine" 2016 Nat Rev Genet 507-522

Baltimore et al 2015 Science

Baltimore D et al "A Prudent Path Forward for Genomic Engineering and Germ Line Gene Modification" 2015 Science 36-38

Baumann 2016 Nano Ethics

Baumann M "CRISPR/Cas9 Genome Editing - New and Old Ethical Issues Arising from a Revolutionary Technology" 2016 Nano Ethics 139-159

Blasimme and Vayena 2016 Perspect Biol Med

Blasimme A and Vayena E "'Tailored-to-you': Public Engagement and the Political Legitimation of Precision Medicine" 2016 Perspect Biol Med 172188 
Burgess et al 2008 Pers Med

Burgess $\mathrm{M}$ et al "Biobanking in British Columbia: Discussions of the Future of Personalized Medicine through Deliberative Public Engagement" 2008 Pers Med 285

Caplan et al2015 Sci Soc

Caplan AL et al "No Time to Waste: The Ethical Challenges Created by CRISPR" 2015 Sci Soc 1421-1426

Carroll 2014 Annu Rev Biochem

Carroll D "Genome Engineering with Targetable Nucleases" 2014 Annu Rev Biochem 409-439

Cavaliere 2017 BMC Medical Ethics

Cavaliere G "A 14-day Limit for Bioethics: The Debate over Human Embryo Research" 2017 BMC Medical Ethics 38

Cavaliere et al 2019 Camb Q Healthc Ethics

Cavaliere $G$ et al "Regulating Genome Editing: For an Enlightened Democratic Governance" 2019 Cam Q Healthc Ethics 76-88

Chambers 2003 Annu Rev Polit Sci

Chambers S "Deliberative Democratic Theory" 2003 Annu Rev Polit Sci 307-326

Cong et al 2013 Science

Cong L et al "Multiplex Genome Engineering Using CRISPR/Cas Systems" 2013 Science 819-823

Cribbs and Perera 2017 YJBM

Cribbs AP and Perera S "Science and Bioethics of CRISPR-Cas9 Gene Editing: An Analysis towards Separating Facts and Fiction" 2017 YJBM625634

Department of Health Ethics in Health Research

Department of Health Ethics in Health Research: Principles, Structures and Processes $2^{\text {nd }}$ ed (Department of Health Pretoria 2015)

Doudna and Charpentier 2014 Science

Doudna JA and Charpentier E "The New Frontier of Genome Engineering with CRISPR-Cas9" 2014 Science 1077

Evans et al 2011 Science

Evans JP et al "Deflating the Genomic Bubble" 2011 Science 861-862 
Feeney et al 2018 AJOB

Feeney $\mathrm{O}$ et al "Patenting Foundational Technologies: Lessons from CRISPR and Other Core Biotechnologies" 2018 AJOB 36-48

Gupta and Musunuru $2014 \mathrm{~J}$ Clin Invest

Gupta RM and Musunuru K "Expanding the Genetic Editing Tool Kit: ZFNs, TALENs, and CRISPR-Cas9" 2014 J Clin Invest 4154-4161

Hopkins 1998 Hastings Centre Report

Hopkins PD "Bad Copies: How Popular Media Represent Cloning as an Ethical Problem" 1998 Hastings Centre Report 6-13

Hsu et al 2014 Cell

Hsu PD et al "Development and Applications of CRISPR-Cas9 for Genome Engineering" 2014 Cell 1262-1278

Hwang et al 2013 Nat Biotechnol

Hwang WY et al "Efficient Genome Editing in Zebrafish Using a CRISPRCas9 System" 2013 Nat Biotechnol 227-229

Ishi 2016 Curr Stem Cell Rep

Ishi T "Somatic Genome Editing for Health: Disease Treatments and Beyond" 2016 Curr Stem Cell Rep 313-320

Jinek et al 2013 eLife

Jinek M et al "RNA-programmed Genome Editing in Human Cells" 2013 eLife https://doi.org/10.7554/eLife.00471.001 accessed 8 February 2021

Jordaan 2012 SAMJ

Jordaan D "Regulatory Crackdown on Stem Cell Therapy: What would the Position be in South Africa?" 2012 SAMJ 226-228

Lander 2015 NEJM

Lander ES "Brave New Genome" 2015 NEJM 5-8

Lander 2016 Cell

Lander ES "The Heroes of CRSIPR" 2016 Cell 18-28

Lander et al 2019 Nature

Lander ES et al "Adopt a Moratorium on Heritable Genome Editing" 2019 Nature 165-168 
Liu et al 2019 Nature

Liu JJ et al "CasX Enzymes Comprise a Distinct Family of RNA-guided Genome Editors" 2019 Nature 218-223

Mali et al 2013 Science

Mali $P$ et al "RNA-guided Human Genome Engineering via Cas9" 2013 Science 823-826

NASEM Heritable Human Genome Editing

National Academy of Sciences, Engineering, and Medicine Heritable Human Genome Editing (National Academies Press Washington 2020)

NASEM Human Genome Editing

National Academies of Sciences, Engineering, and Medicine. Human Genome Editing: Science, Ethics, and Governance (National Academies Press Washington 2017)

NASEM Second International Summit on Human Genome Editing

National Academies of Sciences, Engineering, and Medicine Second International Summit on Human Genome Editing at the University of Hong Kong (National Academies Press Washington 2019)

Nature Medicine 2015 Nat Med

Nature Medicine "Germ line Editing: Time for Discussion" 2015 Nat Med 295

Pillay and Thaldar 2018 SAJBL

Pillay $S$ and Thaldar D "CRISPR: Challenges to South African Biotechnology Law" 2018 SAJBL 89-92

Posner et al 2016 PNAS

Posner S et al "Policy Impact of Ecosystem Services Knowledge" 2016 PNAS 1760-1765

Reardon 2016 Nature

Reardon S "Welcome to the CRISPR Zoo" 2016 Nature 160-163

Sanchez-Rivera and Jacks 2015 Nat Rev Cancer

Sanchez-Rivera FJ and Jacks T "Applications of the CRISPR-Cas9 System in Cancer Biology" 2015 Nat Rev Cancer 387-395

Steiner 1988 Harv Hum Rts YB

Steiner HJ "Political Participation as a Human Right" 1988 Harv Hum Rts YB 77-134 
Townsend 2020 BMC Medical Ethics

Townsend BA "Human Genome Editing: How to Prevent Rogue Actors" 2020 BMC Medical Ethics https://doi.org/10.1186/s12910-020-00527-w accessed 8 February 2021

Van den Belt "Biotechnology"

Van den Belt $\mathrm{H}$ "Biotechnology, the US-EU Dispute and the Precautionary Principle" in Wesseler JHH (ed) Environmental Costs and Benefits of Transgenic Crops (Springer Dordrecht 2005) 185-197

Warnock Report of the Committee of Inquiry

Warnock M Report of the Committee of Inquiry into Human Fertilisation and Embryology (Her Majesty's Stationery Office London 1984)

Warnock 1985 Milbank Mem Fund Q

Warnock M "Moral Thinking and Government Policy: The Warnock Committee on Human Embryology" 1985 Milbank Mem Fund Q 504-522

Wolinetz and Collins 2019 Nature

Wolinetz CD and Collins FS "NIH Supports Call for Moratorium on Clinical Uses of Germline Gene Editing" 2019 Nature 175

Case law

Bato Star Fishing (Pty) Ltd v Minister of Environmental Affairs and Tourism 20044 SA 490 (CC)

Cloete v S 20195 BCLR 544 (CC)

Cool Ideas I 186 CC v Hubbard 20144 SA 474 (CC)

Furman v State of Georgia 408 US 238 (1972)

Natal Joint Municipal Pension Fund v Endumeni Municipality 20124 SA 593 (SCA)

Public Servants Association obo Ubogu v Head, Department of Health, Gauteng 20182 SA 365 (CC)

Rossouw v Sachs 19642 SA 551 (A)

S v Makwanyane 19953 SA 391 (CC) 


\section{Legislation}

Assisted Human Reproduction Act, 2004 (Canada)

Children's Act 38 of 2005

Consumer Protection Act 68 of 2008

Medicines and Related Substances Control Act 101 of 1965

National Health Act 61 of 2003

Protection of Personal Information Act 4 of 2013

Patents Act 57 of 1978

International instruments

United Nations Declaration on Human Cloning (2005)

Government publications

GN R175 in GG 35099 of 2 March 2012

GN R177 in GG 35099 of 2 March 2012

GN R178 in GG 35099 of 2 March 2012

GN R179 in GG 35099 of 2 March 2012

GN R180 in GG 35099 of 2 March 2012

GN R181 in GG 35099 of 2 March 2012

GN R182 in GG 35099 of 2 March 2012

GN R183 in GG 35099 of 2 March 2012

\section{Internet sources}

Centre for Genetics and Society 2018 https://www.geneticsandsociety.org/internal-content/cgs-summary-publicopinion-polls\#igmdata Centre for Genetics and Society 2018 Summary of Public Opinion Polls https://www.geneticsandsociety.org/internal-content/cgs-summary-publicopinion-polls\#igmdata accessed 25 August 2019 
HPCSA 2008 https://www.sada.co.za/media/documents/HPCSA Booklet_14_Biotechnology_Research_in_SA.pdf

Health Professions Council South Africa 2008 Booklet 14: General Ethical Guidelines for Biotechnology Research in South Africa - Guidelines for Good Practice in the Health Care https:/www.sada.co.za/media/ documents/HPCSA_Booklet_14_Biotechnology_Research_in_SA.pdf accessed 2 April 2019

MRC 2001 http://www.mrc.ac.za/sites/default/files/attachments/2016-0629/ethicsbook2.pdf

Medical Research Council 2001 Guidelines on Ethics for Medical Research: Reproductive Biology and Genetic Research (Book 2) http://www.mrc.ac.za/sites/default/files/attachments/2016-06-

29/ethicsbook2.pdf accessed 8 February 2021

UN 2005 https://www.un.org/press/en/2005/ga10333.doc.htm United Nations 2005 General Assembly Adopts United Nations Declaration on Human Cloning by Vote of 84-34-37 https://www.un.org/press/en/2005/ ga10333.doc.htm accessed 8 February 2021

WHO Advisory Committee 2020 https://www.who.int/docs/defaultsource/ethics/governance-framework-for-human-genome-editing-

2ndonlineconsult.pdf?ua $=1$

World Health Organisation Advisory Committee on Developing Global Standards for Governance and Oversight of Human Genome 2020 Editing Human Genome Editing: A Draft Framework for Governance https://www.who.int/docs/default-source/ethics/governance-framework-forhuman-genome-editing-2ndonlineconsult.pdf?ua=1 accessed 8 February 2021

Yong $2018 \mathrm{https}: / / \mathrm{www}$.theatlantic.com/science/archive/2018/11/first-geneedited-babies-have-allegedly-been-born-in-china/576661

Yong ED 2018 A Reckless and Needless Use of Gene Editing on Human Embryos https://www.theatlantic.com/science/archive/2018/11/first-geneedited-babies-have-allegedly-been-born-in-china/576661 accessed 2 April 2019 


\section{List of Abbreviations}

AJOB

Annu Rev Biochem

Annu Rev Polit Sci

BMC Medical Ethics

Camb Q Healthc Ethics

CRISPR

CRISPR-Cas 9

Curr Stem Cell Rep

DNA

$\mathrm{DOH}$

Harv Hum Rts YB

HPCSA

$\mathrm{J}$ Clin Invest

MCA

Milbank Mem Fund Q

MRC

NASEM

Nat Biotechnol

Nat Med

Nat Rev Cancer

Nat Rev Genet

NEJM

$\mathrm{NHA}$

Pers Med

Perspect Biol Med

PNAS

POPIA

Reprod Biol Endocrinol RNA
American Journal of Bioethics

Annual Review of Biochemistry

Annual Review of Political Science

BioMed Central Medical Ethics

Cambridge Quarterly of Healthcare

Ethics

Clustered Regularly-Interspaced Short

Palindromic Repeats

Clustered Regularly-Interspaced Short

Palindromic Repeats (CRISPR)-

associated RNA-guided endonuclease

Cas9

Current Stem Cell Reports

Deoxyribonucleic acid

Department of Health

Harvard Human Rights Yearbook

Health Professions Council South Africa

Journal of Clinical Investigation

Medicines and Related Substances

Control Act 101 of 1965

Milbank Memorial Fund Quarterly

Medical Research Council

National Academy of Sciences,

Engineering, and Medicine

Nature Biotechnology

Nature Medicine

Nature Reviews Cancer

Nature Reviews Genetics

New England Journal of Medicine

National Health Act 61 of 2003

Personalized Medicine

Perspectives in Biology and Medicine

Proceedings of the National Academy of

Sciences

Protection of Personal Information Act 4 of 2013

Reproductive Biology and Endocrinology Ribonucleic acid 
SAHPRA

SAJBL

SAMJ

Sci Rep

Sci Soc

UN

WHO

YJBM
South African Health Products

Regulatory Authority

South African Journal of Bioethics and Law

South African Medical Journal

Scientific Reports

Science and Society

United Nations

World Health Organisation

Yale Journal of Biology and Medicine 